\title{
Health inequalities associated with neighbourhood deprivation in the Quebec population with hypertension in primary prevention of cardiovascular disease
}

\section{A. Vanasse, MD, PhD (1, 2); J. Courteau, PhD (2); S. Asghari, MD, PhD (3); D. Leroux, PhD (4); L. Cloutier, PhD (5)}

This article has been peer reviewed.

Tweet this article

\begin{abstract}
Introduction: Although a number of studies look at prevalence, incidence, treatment, mortality and morbidity in relation to hypertension, few have taken into account the effect of residential neighbourhood on these health indicators in the population diagnosed with hypertension.
\end{abstract}

Objectives: The objective of this study was to measure and compare prevalence, mortality, morbidity, use of medical resources and treatments in relation to the level of material and social deprivation of the area of residence, in a population with a diagnosis of hypertension in primary prevention for cardiovascular disease (CVD) in Quebec in 2006-2007.

Methods: This study is based on a secondary analysis of the medical administrative data of the Quebec health insurance board, the Régie de l'assurance maladie du Québec, for a cohort of 276793 patients aged 30 years or older who had been diagnosed with hypertension in 2006 or 2007, but who did not have a known diagnosis of CVD. The health indicators adjusted for age and sex are prevalence, death, a cardiovascular event, physician visits, emergency department visits and use of antihypertensives. Twenty-five types of areas of residence were obtained by crossing the material and social deprivation quintiles.

Results: Compared with patients living in materially and socially advantaged areas, those living in deprived areas were at $46 \%$ higher risk of a cardiovascular event, $47 \%$ higher risk of being frequent emergency department visitors and $31 \%$ higher risk of being frequent users of a general practitioner's services, but $25 \%$ lower risk of being frequent users of medical specialists' services. Little or no variation was observed in the use of antihypertensives.

Conclusion: This study reveals the existence, in a CVD primary prevention context, of large variations in a number of health indicators among hypertensive patients owing to the material and social deprivation of residential neighbourhood. It is therefore important to take the socioeconomic context into account when planning interventions to prevent CVDs and their consequences.

Keywords: material deprivation, social deprivation, frequent users of services, hypertension, health indicator, cardiovascular disease, urban areas, rural areas

\section{Introduction}

Hypertension is a major public health concern: it is a risk factor for cardiovascular disease (CVD), kidney failure and mortality, and one of the most important in terms of disability-adjusted life years. ${ }^{1-3}$ Kearney et $\mathrm{al}^{4}{ }^{4}$ estimated the global prevalence of hypertension-generally defined as a systolic blood pressure equal to or above $140 \mathrm{mmHg}$ and/or diastolic blood pressure equal to or above $90 \mathrm{mmHg}$ - to be $26 \%$ in the adult population in 2000 , and projected a $24 \%$ increase in developed countries and an $80 \%$ increase in developing countries by 2025. In contrast, Danaei et al. ${ }^{5}$ found the average systolic blood pressure to be decreasing in both sexes worldwide between 1980 and 2008, with the prevalence of age-adjusted hypertension dropping from $33 \%$ to $29 \%$ for men and from $29 \%$ to $25 \%$ for women. This trend varies depending on the country and region, however. In addition, despite this downward trend, the absolute number of people with hypertension has increased as a result of the global population growth and aging. According to an Ontario study, $21 \%$ of the population aged 20 to 79 years had hypertension in 2006, ${ }^{6}$ whereas the 2007-2009 Canadian Health Measures Survey ${ }^{7}$ found that $19 \%$ of Canadians aged between 20 and 79 had hypertension and $20 \%$ had a blood pressure in the prehypertension range. The prevalence of hypertension remains lower in Canada than in the United States (29\%) and England (30\%). ${ }^{8}$

\section{Author references:}

1. Department of Family and Emergency Medicine, Université de Sherbrooke, Sherbrooke, Quebec, Canada 2. Groupe de recherche PRIMUS, Centre de recherche CHUS, Sherbrooke, Quebec, Canada

3. Primary Healthcare Research Unit, Faculty of Medicine, Health Sciences Centre, St. John's, Newfoundland and Labrador, Canada

4. Department of Geography, Université du Québec à Trois-Rivières (UQTR), Trois-Rivières, Quebec, Canada

5. Department of Nursing, Université du Québec à Trois-Rivières (UQTR), Trois-Rivières, Quebec, Canada

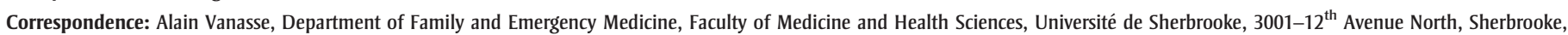
QC J1H 5N4; Tel.: 819-346-1110 ext. 16641; Email: alain.vanasse@usherbrooke.ca 
The Institut national de la santé publique du Québec (INSPQ) ${ }^{9-10}$ found that the adjusted prevalence of hypertension in Quebec rose from $15.8 \%$ in 2000 to $20.3 \%$ in 2007, with the prevalence changing faster for men than for women. At the same time, the adjusted incidence of hypertension fell for both sexes. The mortality rates for people with hypertension also decreased between 2000 and 2007 for both sexes, maybe because of better drug treatments. ${ }^{9-10}$ A recent study $^{11}$ in 17 countries found the prevalence of hypertension to be nearly $40 \%$ in people between the ages of 35 and 70 years, with the definition of hypertension based on the self-reported use of an antihypertensive or on an average blood pressure of at least $140 / 90 \mathrm{mmHg}$ (2 measurements). Less than half $(46.5 \%)$ of the participants in this study were aware of their condition, and only one-third $(32.5 \%)$ of those receiving treatment had controlled blood pressure.

According to the World Health Organization, ${ }^{12}$ many factors or health determinants combine to affect the health of individuals. There are 3 types of health determinants: those that relate to people's individual characteristics (e.g. age, sex, comorbidities); those that relate to the social and physical characteristics of their areas of residence (e.g. neighbourhood socioeconomic status and rurality); and those that relate to the characteristics of the health care system and care practices. ${ }^{13-16}$ Neighbourhood characteristics can affect those behaviours, including eating habits and physical activity, ${ }^{17}$ that affect health. ${ }^{18}$ Other factors likely to have an impact on health are the quality and availability of affordable housing, ${ }^{19}$ poverty, ${ }^{20}$ safety $^{21}$ and the sense of cohesion as a result of living in a well-organized and socially connected neighbourhood. ${ }^{22}$

The link between neighbourhood characteristics (socioeconomic status or rurality) and the prevalence and incidence of hypertension has been previously studied. In their 2013 study, Chow et al. ${ }^{11}$ found that study participants who lived in urban communities in low-income countries were more aware of and treated and controlled their hypertension better than did the participants in rural communities. However, the awareness, treatment and control were similar for rural and urban residents in higher-income countries. In addition, blood pressure control was more frequent in high-income countries $(40.7 \%) .^{11}$ Lee et al. ${ }^{23}$ found a gradient between the prevalence of hypertension and income, whereas Aubé-Maurice et $\mathrm{al}^{24}$ showed that the incidence of hypertension was associated with the neighbourhood material and social deprivation, although this association differed depending on the case identification algorithm.

In short, the association between deprivation-of an individual, area or countryand health indicators such as prevalence and incidence of hypertension are well documented. However, there are few studies on how neighbourhood characteristics affect mortality, morbidity, use of health services and prescription-drug treatment for a population diagnosed with hypertension in primary prevention for CVD. In addition, as a number of current studies do not have the statistical power to adequately evaluate vulnerable populations, ${ }^{25}$ we set out to determine:

- if there is a higher risk of mortality and morbidity in this vulnerable population in deprived areas;

- who are the most frequent users of primary and secondary medical services;

- if people living in deprived areas receive treatment for their hypertension less often than those living in less deprived areas; and

- whether differences exist between urban and small town or rural areas.

Our objectives were to describe and compare the prevalence of hypertension in the primary prevention of CVD in 20062007 in the Quebec population, according to the level of material and social deprivation of the area of residence, as well as their mortality, morbidity, use of medical services and prescription-drug treatment. Because the material and social deprivation of the area generally differs depend- ing on the living environment (urban or rural), comparisons were made both globally and by rurality.

\section{Methods}

\section{Data sources}

We conducted a secondary analysis of medical and administrative data from the list of beneficiaries, the medical services register and the Fichier des hospitalisations Med-Écho of the Quebec health insurance board, the Régie de l'assurance maladie du Québec (RAMQ). ${ }^{26}$ The latter lists each patient's diagnoses, hospital admission and discharge dates, and treatment details. ${ }^{27}$ The medical services register contains the attending physician's encrypted number, the procedure(s) performed, the diagnosis and the date the service was given. The list of beneficiaries includes patient's sex, date of birth and the geographical location of the place of residence (postal code). The Institut de la statistique du Québec death file lists the date and cause of death for all deaths that occurred in Quebec. Other data were provided by the RAMQ through the health care professionals' file (physician's encrypted number and medical specialty), the public prescription drug insurance plan eligibility file (participation start and end dates) and the file on drug services billed by pharmacists to the RAMQ (which contains all the drug reimbursement claims made by people covered by the public plan, with the drug code, the claim date and the length of treatment).

RAMQ covered the costs of medications for about $41 \%$ of the Quebec population in 2006 (i.e. seniors aged 65 years or older, welfare recipients, and everyone not covered by a private prescription-drug insurance plan). Dissemination areas ${ }^{*}$ (DA) were associated with each patient's area of residence based on their postal code. ${ }^{28}$ Data on material and social deprivation indices were provided by the INSPQ. ${ }^{29} \mathrm{DA}$ classification as part of a urban, small town or rural area was based on Statistics Canada data. ${ }^{28}$ Data on DA population counts by age and sex were based on the

* A DA is the smallest standard geographical area within the Census, with a population of 400 to 700 people. 
2006 Census and were provided by Variables Statistics Canada. ${ }^{30}$

This project was approved by the Université de Sherbrooke ethics boards and Quebec's information access commission, the Commission d'accès à l'information.

\section{Population}

The study cohort is made up of all the residents of Quebec aged 30 years or older who, between January 2006 and December 2007, had been hospitalized with a primary or secondary diagnosis of hypertension (ICD-9 ${ }^{\dagger} 401$ or ICD-10* I10) or used at least 3 medical services with a hypertension diagnosis in 365 days of the study period. Although other algorithms have been validated ${ }^{31}$ and have both good sensitivity and good specificity, we did not use them because they involved data from the medical records and prescription-drug files to which we did not have access for all patients. The case definition algorithm for hypertension most similar to ours was validated by Lix et al. ${ }^{32}$ for Manitoba data (1 hospitalization or 2 services in 1 year) with a sensitivity of $51 \%$ and a specificity of $97 \%$.

To keep only primary prevention of CVD patients in the cohort, we excluded cases with the following CVD diagnoses in the 4 years preceding the reference date (the first date with a hypertension diagnosis in the study period): ischemic heart disease (ICD-9 410-414 or ICD-10 I20-I25), heart failure (ICD-9 428 or ICD-10 I50) or a cerebrovascular disease (ICD-9 430-438 or ICD-10 I60-I69). Also excluded were all patients who had been seen by a doctor or hospitalized for pregnancy (ICD-9 630676 and 760-779 or ICD-10 000-099 and Z32-Z39) in the 5 months following the reference date. ${ }^{33}$ Finally, also excluded were patients for whom no DA could be defined or no information on the size of the population of their DA was available, as well as those in a DA for which the material and social deprivation value was unknown.
The first variable examined was the prevalence of hypertension in CVD primary prevention in relation to material and social deprivation. For each sociogeographical unit selected, the prevalence numerator is the size of the study cohort and the prevalence denominator is the population of Quebec aged 30 years or older.

We also calculated the incidence of allcause mortality and that of a given cardiovascular event-CVD mortality or hospitalization for a CVD (ICD-9: 410-414, 428 and 430-438; ICD-10: I20-I25, I50 and I60I69) - for the entire cohort over the 2 years after the reference date. For the other dependent variables, the incidences were calculated based on number of people who survived the two-year period following the reference date. These other dependent variables are all-cause hospitalization; outpatient consultation (for any health problem) with a general practitioner, internist, cardiologist, endocrinologist or nephrologist; an emergency department visit; frequent outpatient medical consultations, regardless of specialty (42 services or more); frequent outpatient visits to a general practitioner (22 services or more); frequent outpatient visits to specialists (4 services or more) or frequent emergency department visits (4 services or more). To better take into account the Quebec context, the thresholds used to define frequent use were based on the population quartiles from a population with hypertension, diabetes or dyslipidemia diagnosed between 2006 and 2007 in Quebec. (Research information available on request.) For example, $25 \%$ (top quartile) of the patients in this population had received at least 22 services from a general practitioner. Patients who used health services above these thresholds were considered frequent users. Naessens et $\mathrm{al}^{34}$ chose to use a threshold of 10 consultations or more per year (with a total of 20 over 2 years) to identify frequent users of primary care. Measuring the proportion of these frequent users of health care is important because the use of care and the associated cost can be attributed to a relatively small fraction of the population. For example, in the United States, $5 \%$ of the population accounts for about $50 \%$ of all health costs. ${ }^{35}$

Finally, for the drug-related dependent variables, we calculated the proportion of prescription-drug users among the people eligible for the provincial drug insurance plan who survived the two-year period following the reference date. These variables are use of an antihypertensive, defined globally and by antihypertensive class (angiotensin-converting enzyme inhibitor, angiotensin II receptor antagonist, diuretic, beta blocker, calcium channel blocker, other). Patients are considered to have used a drug in a specific class if they presented at least one prescription in that class at the pharmacy within 2 years following the reference date.

To determine the rurality of a neighbourhood, we used the Statistical Area Classification developed by Statistics Canada. ${ }^{36}$ Basic Statistical Area Classification units are municipalities. Each municipality belongs to a census metropolitan area (at least 100000 inhabitants), a census agglomeration or small town (between 10000 and 99999 inhabitants), or a rural area or strong-to-noinfluence metropolitan-influenced zone (if the municipality is not classified elsewhere). On the recommendation of Statistics Canada, ${ }^{37}$ for the purpose of this analysis we grouped the small towns and rural areas into a single category, "non-metropolitan areas."

For level of deprivation, the INSPQ has developed a deprivation index using 6 socioeconomic indicators calculated at the DA level. ${ }^{38-42}$ The material component of the index takes into account the proportion of people without a high school diploma, the employment-to-population ratio and the average income, while the social component was calculated using the proportion of people living alone, the proportion of separated, divorced or widowed people, and the proportion of 
lone-parent families. DAs are classified by quintiles (i.e. $20 \%$ of the population), with Quintile 1 (Q1) the most advantaged and Quintile 5 (Q5) the most deprived. These categorizations were conducted separately for the material and social components, and were then combined, resulting in the 25 neighbourhood deprivation classes $(\mathrm{Q} 1 \times \mathrm{Q} 1$ to $\mathrm{Q} 5 \times \mathrm{Q} 5)$.

\section{Statistical analyses}

The analyses were done for the entire cohort and were stratified by type of neighbourhood (metropolitan and nonmetropolitan areas). To determine whether the differences in health indicators between metropolitan and non-metropolitan areas were statistically significant, we used the chi-square test. Given the size of the study cohort $(\mathrm{N}=276$ 793), minimal differences could prove statistically significant. Therefore, we also used the concept of clinical significance, where a variation of $\pm 10 \%$ or more in the health indicators is considered clinically significant. For each dependent variable studied, the proportions were adjusted for age and sex. We measured the variability of the health indicators according to deprivation using a coefficient of variation (CV), which represents the ratio of the standard deviation to the mean. To compare the adjusted proportion of the class of interest (one of the 25 classes of neighbourhood material and social deprivation) and the proportion observed in the least materially and socially deprived class $(\mathrm{Q} 1 \times \mathrm{Q} 1)$, we calculated the relative risk (RR), which indicates the percentage increase or decrease in risk in relation to this class $(\mathrm{Q} 1 \times \mathrm{Q} 1)$ and with which we associated a confidence interval (CI).

\section{Results}

A total of 472558 people aged 30 years or older met our inclusion criteria for the study period (1 January, 2006, to 31 December, 2007) (Figure 1). Of these, 180328 (38.2\%) had been diagnosed with CVD in the 4 years prior to the reference date or had possible pregnancy-related hypertension ( $\mathrm{n}=1757)$ and were excluded. Also excluded were 13680 people for whom the place of residence was invalid or missing or who lived in

FIGURE 1

Selection of the cohort studied

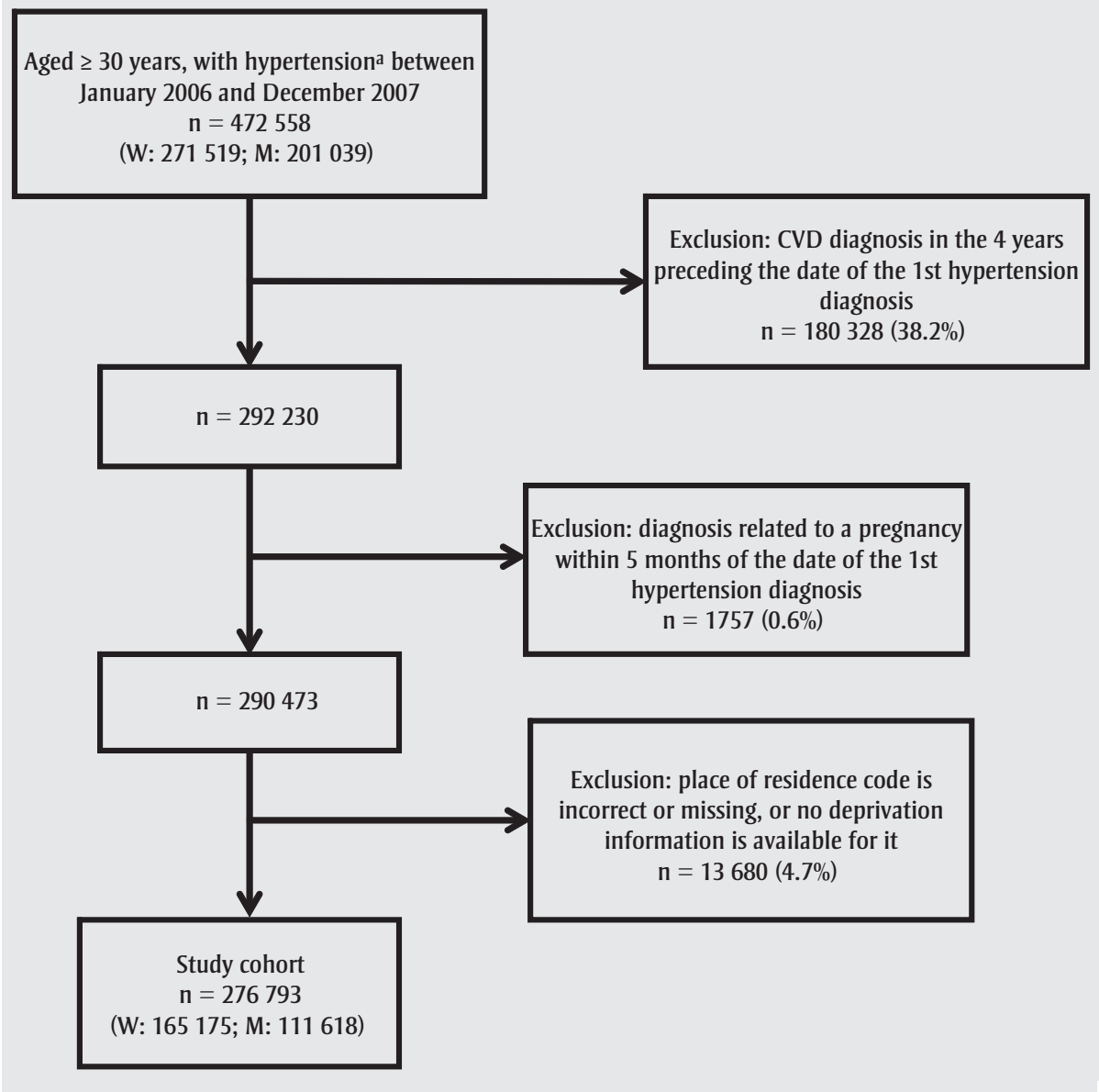

Abbreviations: CVD, cardiovascular disease; ICD, International Classification of Diseases; M, men; W, women.

${ }^{a}$ Hospitalized with a primary or secondary diagnosis of hypertension (ICD-9: 401 or ICD-10: I10) or used at least 3 medical services with a hypertension diagnosis in 365 days during the study period.

DAs for which no socioeconomic information was available. The final cohort included 276793 people.

Of this number, about $70 \%$ were covered by the provincial drug insurance plan on the reference date, mainly because of age (mean age 66 years, with $57 \%$ of the cohort 65 years or older) (Table 1). Twothirds lived in metropolitan areas and onethird in non-metropolitan areas $(12 \%$ in small towns and $20 \%$ in rural areas). This distribution is roughly the same as that of the population of Quebec aged 30 years or older.

The distribution of the cohort according to the neighbourhood material and social deprivation is not uniform, owing to an over-representation of patients in the most deprived areas, in the fourth (Q4) and fifth (Q5) quintiles (Table 1). This would indicate a greater prevalence of hypertension in primary prevention in the deprived areas (Figure 2).

The results of the global analyses and the analyses by rurality are shown in Table 2 . Although nearly all the values in the metropolitan and non-metropolitan areas are statistically significantly different, there is much less clinical significance to these differences (at least $\pm 10 \%$ ), including for the use of drugs. Among the results that indicate a clinically significant difference are the proportion of all-cause deaths and hospitalizations as well as the proportion of cardiovascular events, with the metropolitan areas having lower values than the non-metropolitan areas. In addi- 
TABLE 1

Characteristics of the study cohort $(n=276$ 793) by rurality

\begin{tabular}{|c|c|c|c|c|}
\hline \multirow[t]{2}{*}{ Characteristics } & \multirow[t]{2}{*}{ Total } & \multirow{2}{*}{$\begin{array}{c}\text { Metropolitan } \\
\text { areas }^{\mathrm{a}}\end{array}$} & \multicolumn{2}{|c|}{ Non-metropolitan areas } \\
\hline & & & Small towns & Rural areas \\
\hline Cohort studied, n (\%) & $276793(100)$ & $188107(68.0)$ & $33127(12.0)$ & $55559(20.0)$ \\
\hline Average age (SD), years & $66.3(12.7)$ & $66.0(12.7)$ & $67.0(12.5)$ & $66.7(12.4)$ \\
\hline \multicolumn{5}{|l|}{ Age group in years, $n(\%)$} \\
\hline$<65$ & $117844(42.6)$ & $81793(43.5)$ & $13231(39.9)$ & $22820(41.1)$ \\
\hline$\geq 65$ & $158949(57.4)$ & $106314(56.5)$ & $19896(60.1)$ & $32739(58.9)$ \\
\hline \multicolumn{5}{|l|}{ Sex, n (\%) } \\
\hline Female & $165175(59.7)$ & $112663(59.9)$ & $20299(61.3)$ & $32213(58.0)$ \\
\hline Male & $111618(40.3)$ & $75444(40.1)$ & $12828(38.7)$ & $23346(42.0)$ \\
\hline \multicolumn{5}{|c|}{ Material deprivation quintile, n (\%) } \\
\hline Q1 ${ }^{\mathrm{c}}$ & 48585 (17.6) & $44908(23.9)$ & $2097(6.3)$ & $1580(2.8)$ \\
\hline Q2 & $53203(19.2)$ & $42833(22.8)$ & $5887(17.8)$ & $4483(8.1)$ \\
\hline Q3 & $57577(20.8)$ & $39721(21.1)$ & $8661(26.1)$ & $9195(29.2)$ \\
\hline Q4 & $59302(21.4)$ & $34506(18.3)$ & $8562(25.8)$ & $16234(29.2)$ \\
\hline Q5 ${ }^{\mathrm{d}}$ & $58126(21.0)$ & 26139 (13.9) & $7920(23.9)$ & $24067(43.3)$ \\
\hline \multicolumn{5}{|c|}{ Social deprivation quintile, $\mathrm{n}(\%)$} \\
\hline $\mathrm{Q1}^{\mathrm{c}}$ & $47248(17.1)$ & $29772(15.8)$ & $4438(13.4)$ & $13038(23.5)$ \\
\hline Q2 & $50861(18.4)$ & $28227(15.0)$ & $5403(16.3)$ & $17231(31.0)$ \\
\hline Q3 & $55106(19.9)$ & $33892(18.0)$ & $6532(19.7)$ & $14682(26.4)$ \\
\hline Q4 & $60820(22.0)$ & $45199(24.0)$ & $7417(22.4)$ & $8204(14.8)$ \\
\hline Q5 ${ }^{d}$ & $62758(22.7)$ & $51017(27.1)$ & $9337(28.2)$ & $2404(4.3)$ \\
\hline \multicolumn{5}{|c|}{ Combinations of material and social deprivation quintiles, $\mathrm{n}(\%)$} \\
\hline $\mathrm{Q} 1 \times \mathrm{Q} 1$ & $8900(3.2)$ & 8368 (4.4) & $338(1.0)$ & $194(0.4)$ \\
\hline $\mathrm{Q} 1 \times \mathrm{Q} 2$ & 7340 (2.6) & 6629 (3.5) & 439 (1.3) & $272(0.5)$ \\
\hline $\mathrm{Q} 1 \times \mathrm{Q} 3$ & 9143 (3.3) & 8020 (4.3) & 494 (1.5) & 629 (1.1) \\
\hline $\mathrm{Q} 1 \times \mathrm{Q} 4$ & $11137(4.0)$ & 10488 (5.6) & 321 (1.0) & $328(0.6)$ \\
\hline $\mathrm{Q} 1 \times \mathrm{Q} 5$ & 12065 (4.4) & 11403 (6.1) & 505 (1.5) & $157(0.3)$ \\
\hline $\mathrm{Q} 2 \times \mathrm{Q} 1$ & 8649 (3.1) & 7177 (3.8) & $813(2.4)$ & 659 (1.2) \\
\hline $\mathrm{Q} 2 \times \mathrm{Q} 2$ & 9693 (3.5) & 7313 (3.9) & 1158 (3.5) & $1222(2.2)$ \\
\hline $\mathrm{Q} 2 \times \mathrm{Q} 3$ & 10745 (3.9) & $7962(4.2)$ & 1555 (4.7) & $1228(2.2)$ \\
\hline $\mathrm{Q} 2 \times \mathrm{Q} 4$ & 12357 (4.5) & 9924 (5.3) & 1220 (3.7) & $1213(2.2)$ \\
\hline $\mathrm{Q} 2 \times \mathrm{Q} 5$ & 11759 (4.2) & 10457 (5.6) & 1141 (3.4) & $161(0.3)$ \\
\hline $\mathrm{Q} 3 \times \mathrm{Q} 1$ & 9375 (3.4) & 6390 (3.4) & $1327(4.0)$ & $1658(3.0)$ \\
\hline $\mathrm{Q} 3 \times \mathrm{Q} 2$ & 10888 (3.9) & 6186 (3.3) & 1755 (5.3) & 2947 (5.3) \\
\hline $\mathrm{Q} 3 \times \mathrm{Q} 3$ & 12172 (4.4) & 7838 (4.2) & 1683 & 2651 (4.8) \\
\hline $\mathrm{Q} 3 \times \mathrm{Q} 4$ & 12797 (4.6) & 9165 (4.9) & $2081(6.3)$ & 1551 (2.8) \\
\hline $\mathrm{Q} 3 \times \mathrm{Q} 5$ & $12345(4.5)$ & 10142 (5.4) & 1815 (3.6) & $388(0.7)$ \\
\hline $\mathrm{Q} 4 \times \mathrm{Q} 1$ & 9636 (3.5) & $5087(2.7)$ & 1183 (3.6) & 3366 (6.1) \\
\hline $\mathrm{Q} 4 \times \mathrm{Q} 2$ & 10445 (3.8) & 4564 (2.4) & 1132 (3.4) & 4749 (8.6) \\
\hline $\mathrm{Q} 4 \times \mathrm{Q} 3$ & 12305 (4.4) & $5970(3.2)$ & 1727 (5.2) & 4608 (8.3) \\
\hline $\mathrm{Q} 4 \times \mathrm{Q} 4$ & 13429 (4.8) & 8347 (4.4) & $2401(7.2)$ & 2681 (4.8) \\
\hline $\mathrm{Q} 4 \times \mathrm{Q} 5$ & 13487 (4.9) & 10538 (5.6) & 2119 (6.4) & 830 (1.5) \\
\hline $\mathrm{Q} 5 \times \mathrm{Q} 1$ & 10688 (3.9) & 2750 (1.5) & 777 (2.4) & 7161 (12.9) \\
\hline $\mathrm{Q} 5 \times \mathrm{Q} 2$ & $12495(4.5)$ & 3535 (1.9) & 919 (2.8) & 8041 (14.5) \\
\hline $\mathrm{Q} 5 \times \mathrm{Q} 3$ & 10741 (3.9) & $4102(2.2)$ & $1073(3.2)$ & $5566(10.0)$ \\
\hline
\end{tabular}

Continued on the following page tion, a larger proportion of metropolitan area patients consult specialists, but a smaller proportion visit emergency departments.

Table 3 shows the variations for each health indicator after adjustment for age and sex within the 25 neighbourhood deprivation classes, overall and by rurality (metropolitan and non-metropolitan areas). Among the indicators that vary greatly with deprivation are the proportion of deaths and of cardiovascular events, the proportion of frequent visits to general practitioners and medical specialists, as well as the proportion of frequent visits to emergency departments. Little or no variation is seen in the use of antihypertensive drugs.

Compared with patients living in materially and socially advantaged areas $(\mathrm{Q} 1 \times \mathrm{Q} 1)$, patients living in the most materially and socially deprived areas (Q5 $\times$ Q5) were at a $58 \%$ higher risk of dying $(\mathrm{RR}=1.58,95 \%$ CI: $1.41-1.77), 46 \%$ higher risk of a cardiovascular event $(\mathrm{RR}=1.46,95 \% \mathrm{CI}$ : 1.29-1.65), $47 \%$ more at risk of being frequent emergency department visitors $(\mathrm{RR}=1.47,95 \% \mathrm{CI}: 1.40-1.55)$, and $31 \%$ more at risk of being frequent users of a general practitioner's services $(\mathrm{RR}=1.31,95 \%$ CI: 1.25-1.38) (Table 3). However, those patients living in the most materially and socially deprived areas had $25 \%$ less chance of being frequent users of medical specialists' services $(\mathrm{RR}=0.75$, 95\% CI: 0.71-0.79).

Figure 2 shows the variations observed in the prevalence of hypertension in primary prevention of CVD according to material and social deprivation. This graph helps visualize variations that relate to an area's material deprivation and those that relate to its social deprivation, notably a significant gradient in prevalences toward the most deprived areas. Once adjusted for age and sex, however, the distribution by area type is much more uniform, although the gradient persists in the metropolitan areas.

Figures 3 to 5 show the variations for a selection of health indicators with a relatively high CV (Table 2), overall (Figure 3) and by rurality (Figures 4 and 5). The indicators adjusted for age and sex that 
TABLE 1 (continued)

Characteristics of the study cohort $(n=276$ 793) by rurality

\begin{tabular}{ccccr} 
Characteristics & Total & $\begin{array}{c}\text { Metropolitan } \\
\text { areas }^{2}\end{array}$ & \multicolumn{2}{c}{ Non-metropolitan areas } \\
\cline { 4 - 5 } & & Small towns & Rural areas \\
\hline Q5 $\times$ Q4 & $11110(4.0)$ & $7275(3.9)$ & $1394(4.2)$ & $2431(4.4)$ \\
Q5 $\times$ Q5 & $13102(4.7)$ & $8477(4.5)$ & $3757(11.3)$ & $868(1.6)$ \\
\hline
\end{tabular}

${ }^{\text {a }}$ Equivalent to a census metropolitan area ( $\geq 100000$ inhabitants). ${ }^{36}$

b Small town (10 000-99 999 inhabitants) or census agglomeration and rural area or strong-to-no-influence metropolitaninfluenced zone grouped into a single category on the recommendation of Statistics Canada. ${ }^{37}$

c Most advantaged.

d Most deprived. present a significant general gradient from the least deprived areas to the most deprived areas (Figure 3 ) are the proportion of deaths, the proportion of cardiovascular events and the proportion of frequent users of outpatient services (general practitioner, emergency). The relationship is inverse for the adjusted proportion of frequent users of medical specialists' services, as people living in the most advantaged areas use specialists' services more frequently. The 2 types of deprivation seem

FIGURE 2

Inequalities in the prevalence of hypertension in CVD primary prevention by neighbourhood deprivation and rurality (metropolitan or non-metropolitan areas): relative risks
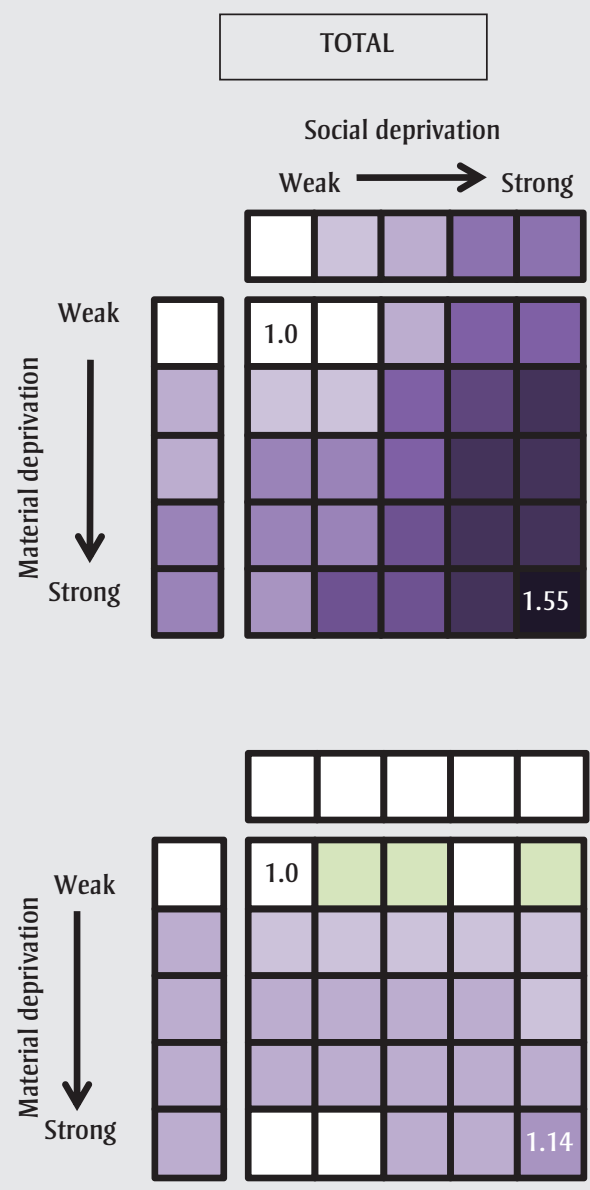

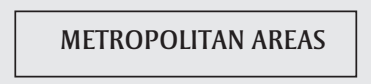

Social deprivation
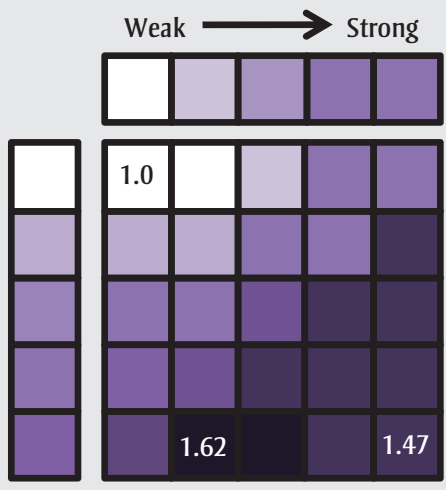

Crude prevalence of hypertension
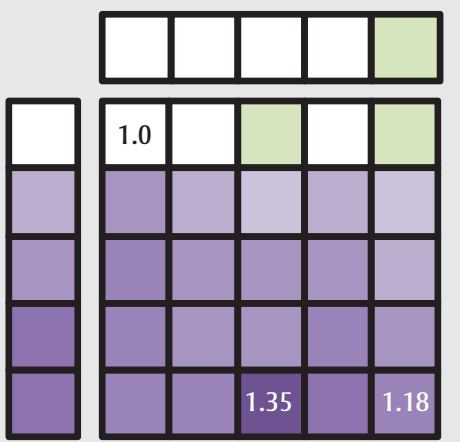

Prevalence of hypertension adjusted for age and sex

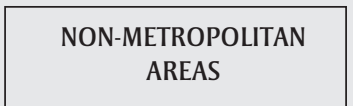

Social deprivation
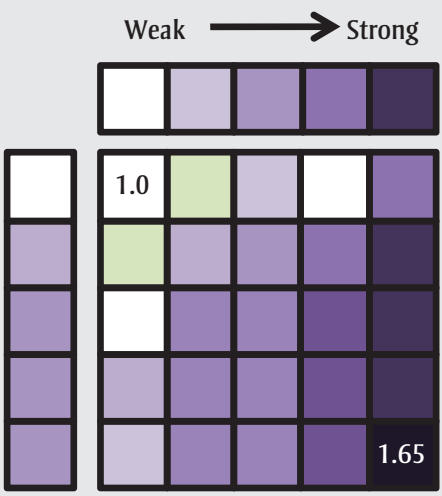

1.65

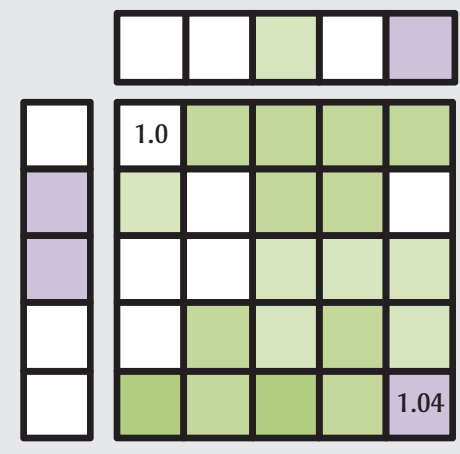

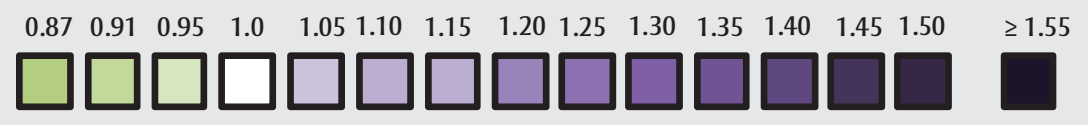

RR

Abbreviations: CVD, cardiovascular disease; RR, relative risk.

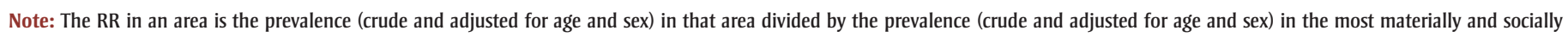
advantaged area. 
TABLE 2

Description of the health indicators in patients ( $\geq 30$ years) with hypertension, in primary prevention of CVD, overall and by rurality (metropolitan or non-metropolitan areas), Quebec, January 2006-December 2007

\begin{tabular}{|c|c|c|c|c|c|c|c|c|c|c|c|}
\hline \multirow[t]{2}{*}{ Health indicators ${ }^{\mathrm{a}}$} & \multicolumn{3}{|c|}{ Total } & \multicolumn{3}{|c|}{ Metropolitan areas ${ }^{\mathbf{b}}$} & \multicolumn{3}{|c|}{ Non-metropolitan areas ${ }^{c}$} & \multirow[t]{2}{*}{ p-value ${ }^{d}$} & \multirow{2}{*}{$\begin{array}{l}\text { Variation } \\
{\text { (as \% })^{\mathrm{e}}}^{\text {(n) }}\end{array}$} \\
\hline & n & $\mathbf{N}$ & $\%$ & $\mathbf{n}$ & $\mathbf{N}$ & $\%$ & n & $\mathbf{N}$ & $\%$ & & \\
\hline $\begin{array}{l}\text { Prevalence of hypertension in } \\
\text { primary prevention of CVD }\end{array}$ & 276793 & 4697515 & 5.9 & 188107 & 3143625 & 6.0 & 88686 & 1553415 & 5.7 & $<.001$ & -5.0 \\
\hline Death & 15104 & 276793 & 5.5 & 9677 & 188107 & 5.1 & 5427 & 88686 & 6.1 & $<.001$ & 19.6 \\
\hline Cardiovascular event & 14050 & 276793 & 5.1 & 8665 & 188107 & 4.6 & 5385 & 88686 & 6.1 & $<.001$ & 32.6 \\
\hline All-cause hospitalization & 87395 & 261689 & 33.4 & 56387 & 178430 & 31.6 & 31008 & 83259 & 37.2 & $<.001$ & 17.7 \\
\hline General practitioner $(\geq 1)$ & 256657 & 261689 & 98.1 & 174853 & 178430 & 98.0 & 81804 & 83259 & 98.3 & $<.001$ & 0.3 \\
\hline Specialist $(\geq 1)$ & 103207 & 261689 & 39.4 & 73809 & 178430 & 41.4 & 29398 & 83259 & 35.3 & $<.001$ & -14.7 \\
\hline Cardiologist $(\geq 1)$ & 64140 & 261689 & 24.5 & 47873 & 178430 & 26.8 & 16267 & 83259 & 19.5 & $<.001$ & -27.2 \\
\hline Internist $(\geq 1)$ & 42269 & 261689 & 16.2 & 27766 & 178430 & 15.6 & 14503 & 83259 & 17.4 & $<.001$ & 11.5 \\
\hline Emergency departments $(\geq 1)$ & 119916 & 261689 & 45.8 & 76171 & 178430 & 42.7 & 43745 & 83259 & 52.5 & $<.001$ & 22.9 \\
\hline Specialists $(\geq 4)$ & 48899 & 261689 & 18.7 & 36713 & 178430 & 20.6 & 12186 & 83259 & 14.6 & $<.001$ & -29.1 \\
\hline Emergency departments $(\geq 4)$ & 63992 & 261689 & 24.5 & 41131 & 178430 & 23.1 & 22861 & 83259 & 27.5 & $<.001$ & 19.0 \\
\hline Antihypertensive & 175204 & 183156 & 95.7 & 115376 & 120833 & 95.5 & 59828 & 62323 & 96.0 & $<.001$ & 0.5 \\
\hline ACEI/ARB & 136061 & 183156 & 74.3 & 89617 & 120833 & 74.2 & 46444 & 62323 & 74.5 & .0991 & 0.4 \\
\hline Diuretic & 117660 & 183156 & 64.2 & 78632 & 120833 & 65.1 & 39028 & 62323 & 62.6 & $<.001$ & -3.8 \\
\hline Calcium channel blocker & 85305 & 183156 & 46.6 & 55288 & 120833 & 45.8 & 30017 & 62323 & 48.2 & $<.001$ & 5.2 \\
\hline Beta blocker & 63678 & 183156 & 34.8 & 41139 & 120833 & 34.0 & 22539 & 62323 & 36.2 & $<.001$ & 6.5 \\
\hline
\end{tabular}

Abbreviations: ACEI, angiotensin-converting enzyme inhibitor; ARB, angiotensin receptor blocker II; CVD, cardiovascular disease.

Note: The bolded indicators indicate a variation of $\geq 10 \%$ between the values for the metropolitan areas and those for the non-metropolitan areas.

a Calculated in the 2 years following the reference date.

b Equivalent to a census metropolitan area ( $\geq 100000$ inhabitants).

c Small towns (10 000-99 999 inhabitants) and rural areas.

d Chi-square test for the difference in proportion between metropolitan and non-metropolitan areas.

e Percentage variation between the rate obtained for non-metropolitan areas and that obtained for metropolitan areas.

to play an equivalent role for some indicators (proportion of deaths, proportion of frequent users of general practitioners' services), while for other indicators (proportion of cardiovascular events, proportion of frequent emergency department visitors or frequent users of specialists' services) material deprivation predominates.

The gradients observed in the metropolitan areas (Figure 4) are similar to those seen overall (Figure 3), probably because these areas account for two-thirds of the cohort studied. The analyses stratified according to rurality reveal larger variations in the non-metropolitan areas (Figure 5) than in the metropolitan areas (Figure 4). These variations are not surprising because samples are smaller in these areas, resulting in a larger variance in the estimation of proportions. Overall, however, for most of the variables studied, the results are consistent, except perhaps for mortality and cardiovascular events, where greater instability in the estimates is observed.

\section{Discussion}

This study shows significant variations for a number of health indicators, depending on the area's material and social deprivation. Even after adjusting for age and sex, the risk of death was higher by $58 \%$, the risk of a cardiovascular event higher by $46 \%$, the risk of hospitalization (all causes) higher by $18 \%$ and the prevalence of hypertension higher by $14 \%$ for people living in the most materially and socially deprived areas $(\mathrm{Q} 5 \times \mathrm{Q} 5)$ than for people living in the least materially and socially deprived areas $(\mathrm{Q} 1 \times \mathrm{Q} 1)$. In addition, the adjusted proportion of frequent users of primary care services was much larger in the more deprived areas, with $47 \%$ more frequent emergency department visitors and $31 \%$ more frequent users of general practitioners' services. Previous studies have shown that people with a lower socioeconomic status make greater use of outpatient medical services, including emergency department services. ${ }^{43}$ In our study, the patients in the most deprived areas not only visited emergency departments more frequently, confirming the results of another Canadian study, ${ }^{44}$ but also consulted general practitioners more 


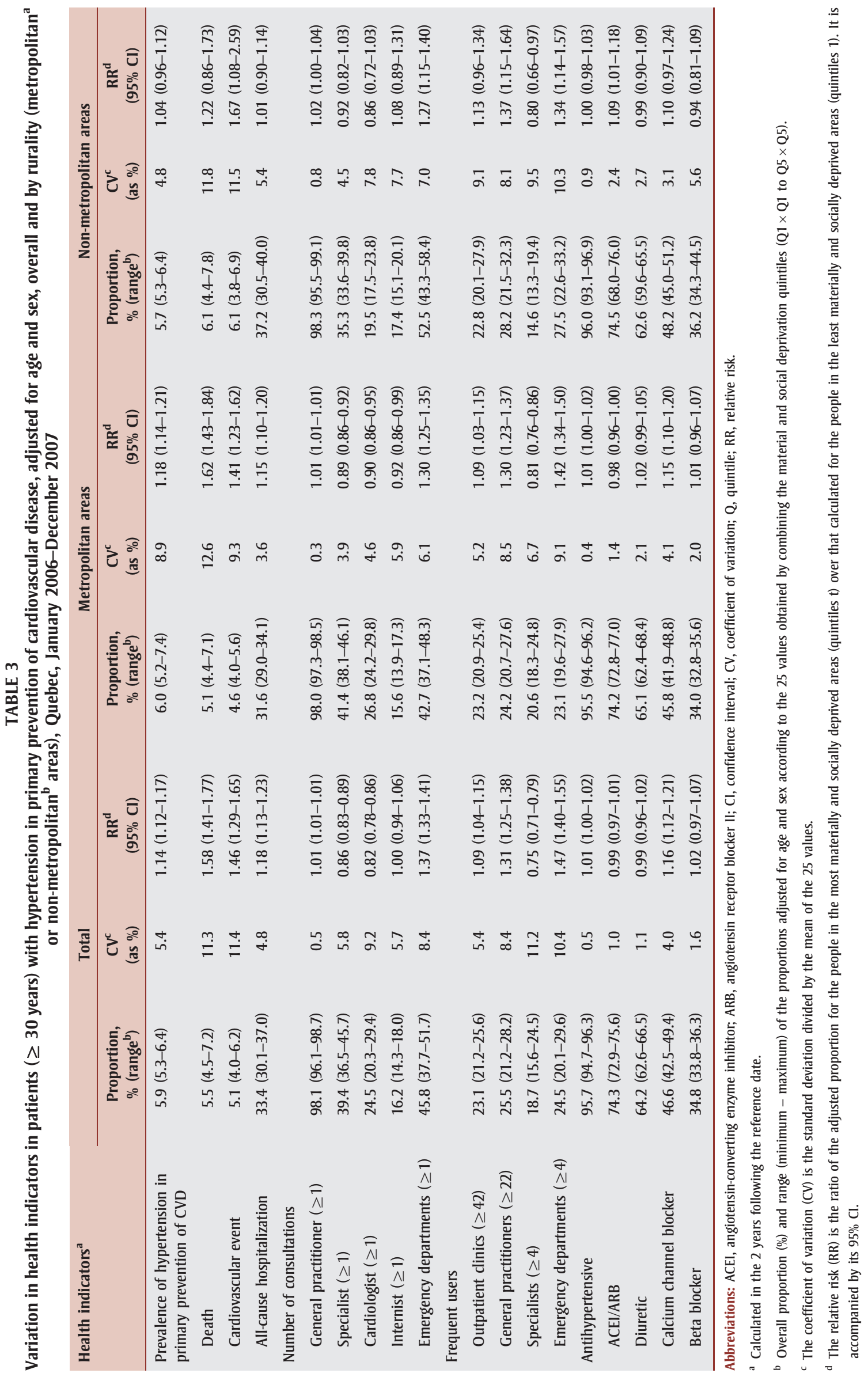


FIGURE 3

Health inequalities of patients with hypertension, by neighbourhood deprivation: relative risks
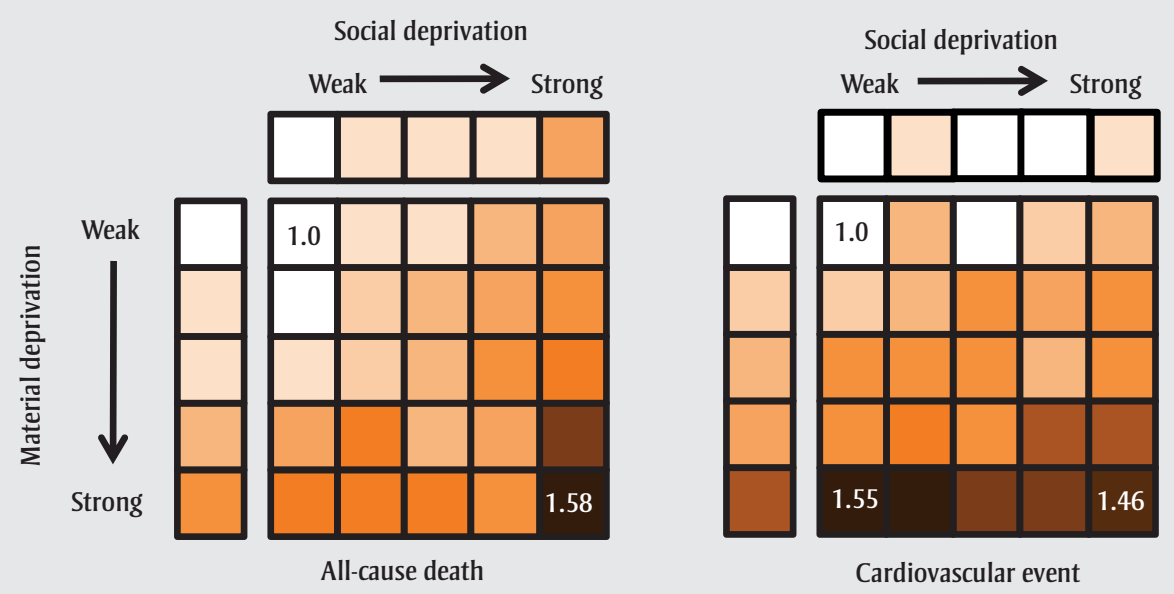

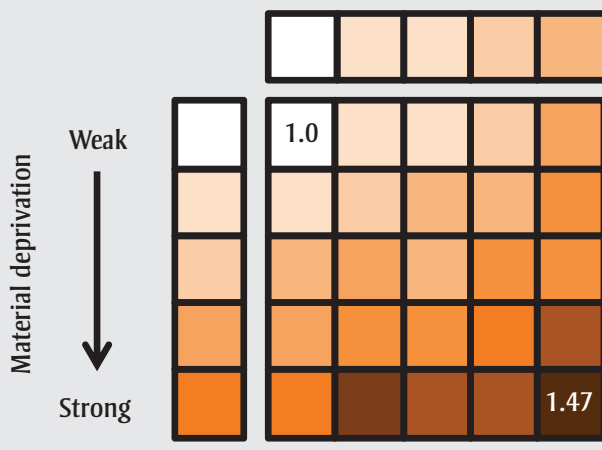

Frequent visitors to the emergency department

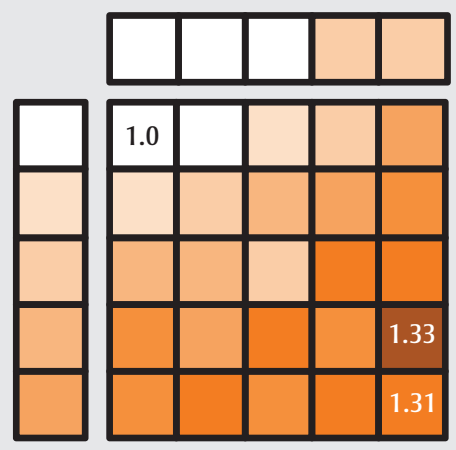

Frequent users of general practitioners' services

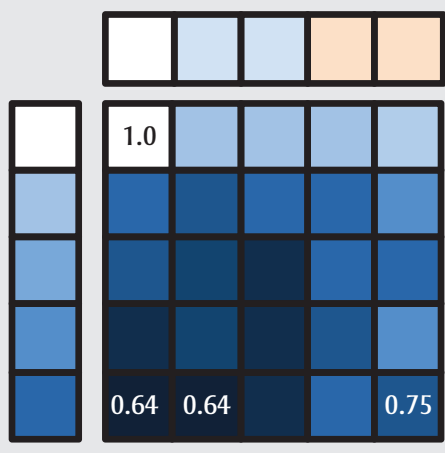

Frequent users of specialists' services

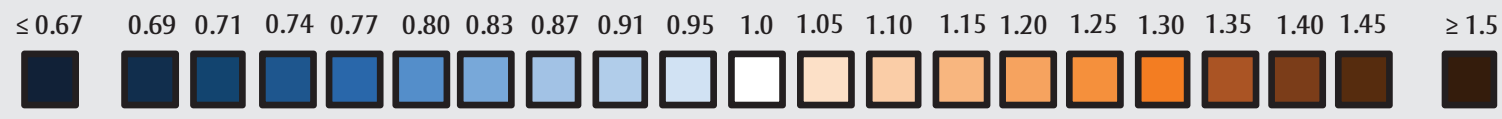

RR

Abbreviation: RR, relative risk.

Note: The RR in an area is the proportion adjusted for age and sex in that area divided by the proportion adjusted for age and sex in the most materially and socially advantaged area.

frequently. We also saw that the proportion of frequent users of specialty services was larger in the most advantaged areas. These variations were also present in the analyses stratified by metropolitan and non-metropolitan area. The lack of variation (or the small variation) seen in the use of antihypertensives may point to the favourable impact of the provincial policy of universal access to drugs.

In short, a large proportion of patients with hypertension who have no history of CVD and live in materially and socially deprived areas experience more serious consequences than those living in advan- taged areas, even though they receive equivalent pharmacotherapy.

In our study, the prevalence of hypertension in CVD primary prevention is estimated at $5.9 \%$ over the 2 years studied (2006-2007). Our estimate is much lower than the prevalence of hypertension calculated by the INSPQ ${ }^{10}$ for the same period $(20.3 \%)$ or the prevalence estimated by Lix et al. ${ }^{32}$ for 2002-2003 $(10.0 \%)$. However, the populations studied differed: we included only patients with hypertension without a history of CVD, thus reducing the cohort by nearly $38 \%$ (Figure 1). In addition, we used just one diagnostic code (ICD-9: 401 and ICD10: I10) in our study to identify hypertension cases, as did Lix et al., ${ }^{32}$ while the INSPQ expanded the hypertension codes to include those related to other pathologies (heart disease, renal disease, hypertensive heart and renal disease, and secondary hypertension [ICD-9: 402-405 and ICD-10: I11-I13 and I15]). Finally, the algorithm we used to identify hypertension cases (3 diagnoses in 1 year or 1 hospitalization) was more specific than those used by the INSPQ ( 2 diagnoses in 2 years or 1 hospitalization) and by Lix et al. ${ }^{32}$ ( 2 diagnoses in 1 year or 1 hospitalization). 
FIGURE 4

Health inequalities of patients with hypertension, by neighbourhood deprivation in metropolitan areas: relative risks

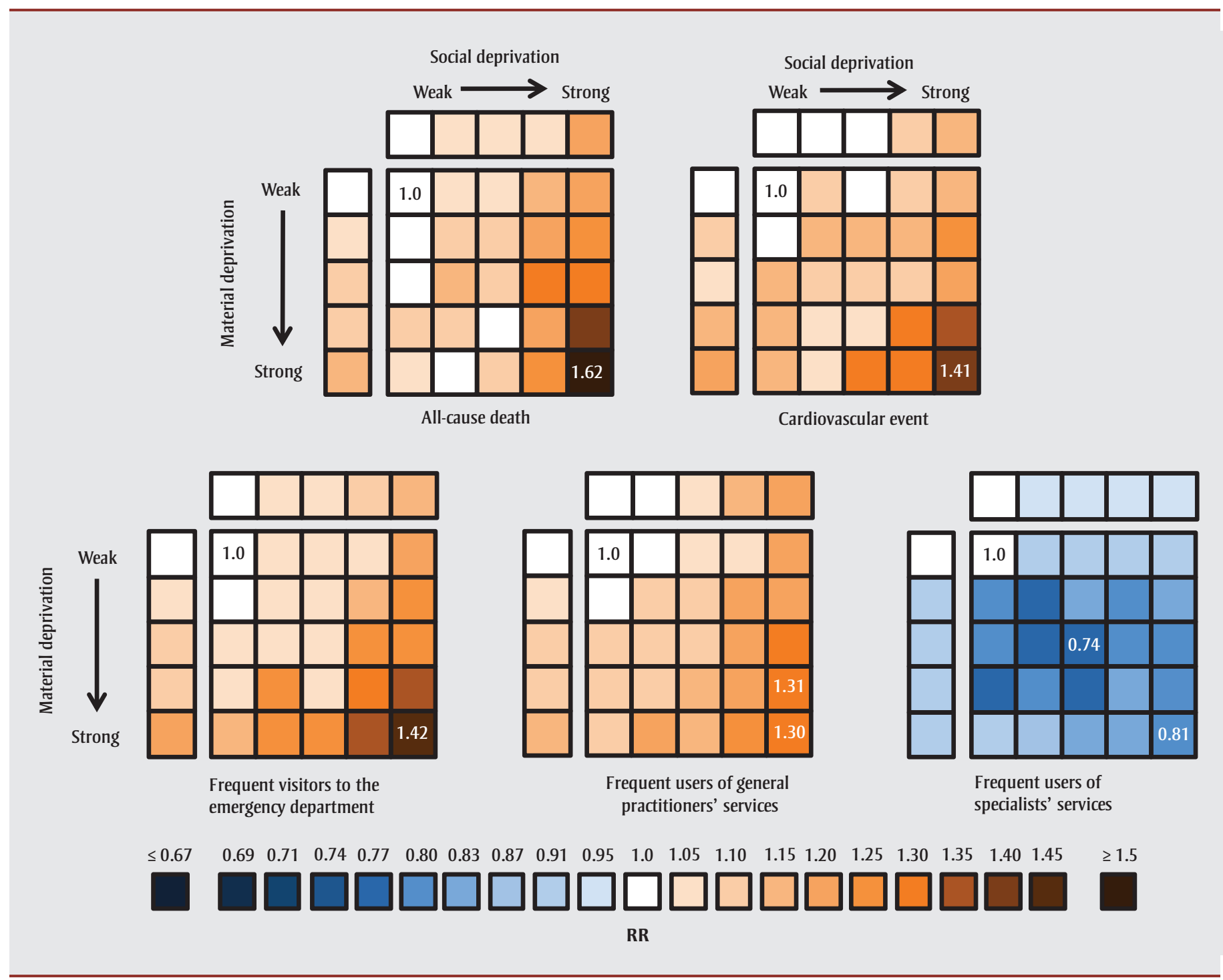

Abbreviation: RR, relative risk.

Note: The RR in an area is the proportion adjusted for age and sex in that area divided by the proportion adjusted for age and sex in the most materially and socially advantaged area.

We should also point out that $60 \%$ of the cohort were women. Women use health services more frequently than do men ${ }^{45-47}$ and are therefore more likely to be diagnosed with hypertension and to be detected by our selection algorithm. In addition, we excluded all patients who had been diagnosed with CVD, which occurs in men more frequently than in women. ${ }^{48-49}$

The gradient in the rates of prevalence of hypertension in primary prevention of CVD according to the neighbourhood level of deprivation is evident and reflects, in good part, a real difference in the age and sex distribution in those areas (Figure 2). This is illustrated by a significant decrease in the gradient between the adjusted and unadjusted results. However, our results for prevalence differ from those published by the INSPQ, where there was a gradient in the hypertension incidence rates from the least materially deprived to the most materially deprived for women only, with an inverse gradient for social deprivation for both sexes. ${ }^{50}$

Many studies have looked at the link between deprivation and certain health indicators. The health indicators related specifically to hypertension include inci- dence, ${ }^{10}$ prevalence, ${ }^{51-53}$ treatments ${ }^{54}$ and hypertension care appropriateness. ${ }^{55}$ Hammouche et al. ${ }^{55}$ proved that study participants with hypertension living in deprived areas in the United Kingdom received care that was at least as good, if not better, than did those living in advantaged areas. The absence of a link between deprivation and the use of antihypertensives in our study is consistent with the results of Hammouche et al. ${ }^{55}$ but not with those of Pears et al. ${ }^{54}$ in Scotland. This absence of a correlation between the use of certain drugs and deprivation was also observed for a cohort of patients with schizophrenia 
FIGURE 5

Health inequalities of patients with hypertension, by neighbourhood deprivation in non-metropolitan areas: relative risks

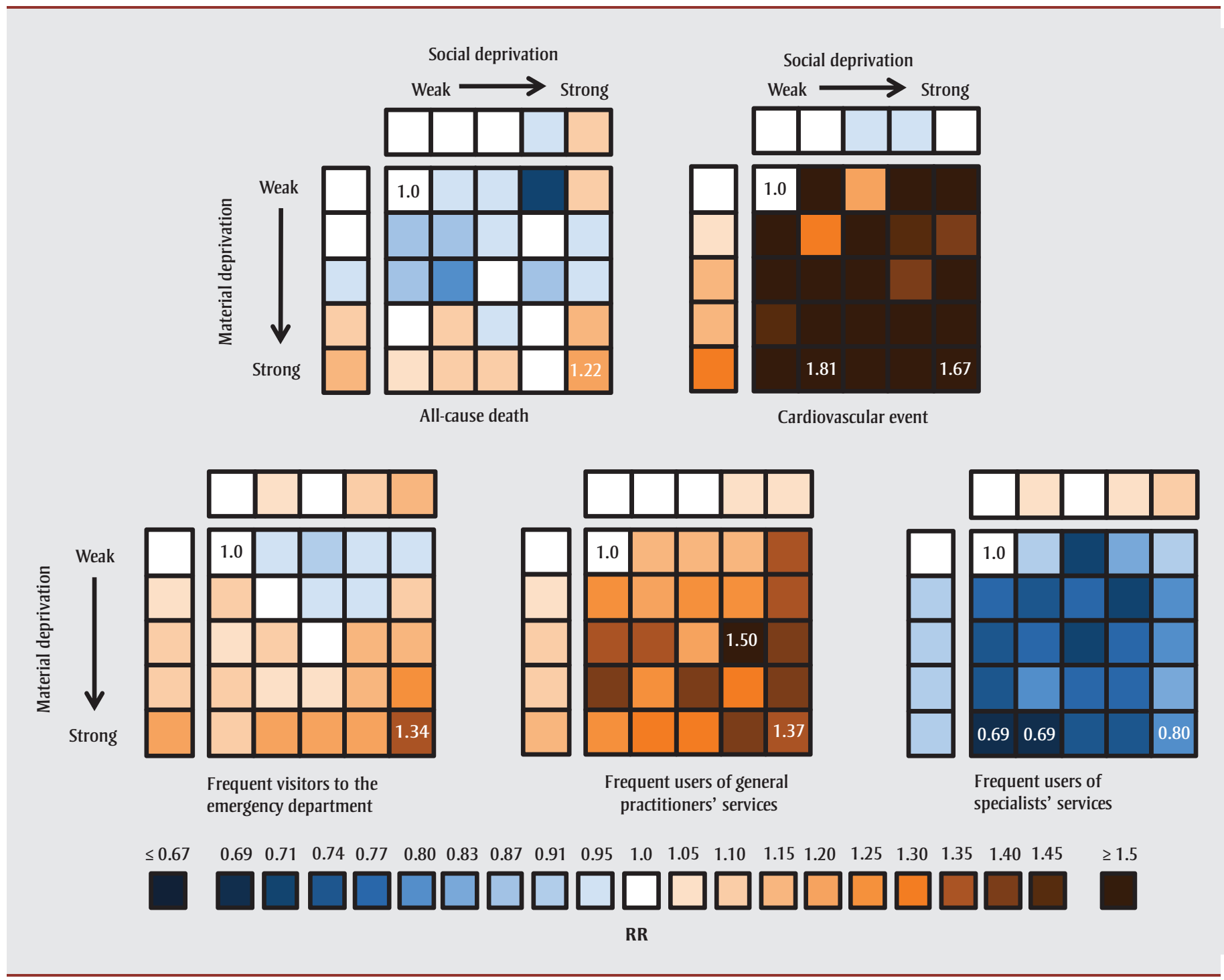

Abbreviation: RR, relative risk.

Note: The RR in an area is the proportion adjusted for age and sex in that area divided by the proportion adjusted for age and sex in the most materially and socially advantaged area.

who took antipsychotic drugs, ${ }^{56}$ and this may point to the effectiveness of the provincial policy of universal access to drugs.

\section{Strengths and limitations}

The greatest strength of our study is that we analysed the entire population of Quebec with a hypertension diagnosis but no known CVD diagnosis. In addition, we compared a large range of health indicators according to 25 area types, ranging from the most materially and socially advantaged to the most materially and socially deprived. However, this study has a number of limitations. First, as we said earlier, the algorithm used is very specific, but not very sensitive, with the result that actual prevalence is underestimated. Nevertheless, we believe that this inclusion bias makes the analyses more robust with regard to the other health indicators because our cohort has very few false positives. In addition, a large number of people with hypertension are not diagnosed $^{11}$ and are therefore not taken into account in our cohort; this is also the case for patients who saw only doctors who work on an hourly rate-for example, in a local community service centre. In 20062007 , as many as $12 \%$ of general practi- tioners worked in a local community service centre. ${ }^{57}$

Second, because the results for drugs relate to only $70 \%$ of the cohort we studied (183 156 patients out of 276793 covered by the provincial drug insurance plan), our results should not be generalized to the overall population with hypertension (selection bias). Further, people aged under 65 years who are socioeconomically deprived are overrepresented in this subpopulation. For this age category, the RAMQ covers all social assistance recipients and all people not covered by a private drug insurance plan. 


\section{Conclusion}

This study demonstrates the existence of significant variations for a number of health indicators among patients with hypertension in primary prevention of CVD according to their neighbourhood material and social deprivation. Some of the indicators, such as deaths from all causes and the incidence of cardiovascular events, can lead to a risk increase of up to $58 \%$ in the most deprived areas, compared with the least deprived, even though there is little or no variation in the use of antihypertensives and the patients in the most deprived areas seem to receive equally good primary care. In a context in which the burden of chronic disease is growing, such health inequalities have major public health implications. This study again shows the importance of taking socioeconomic status into account when planning interventions to prevent CVDs and their consequences. A better understanding of the processes underlying the social inequalities of health in relation to areas of residence is an essential area of public health research.

\section{Acknowledgements}

This project was funded by the Canadian Institutes of Health Research (CIHR). Alain Vanasse receives funding from the Department of Family Medicine and Emergency Medicine of the Université de Sherbrooke, the Centre de recherche CHUS and the Fonds de recherche du Québec - Santé (FRQS).

\section{References}

1. Ezzati M, Lopez AD, Rodgers A, et al. Selected major risk factors and global and regional burden of disease. Lancet. 2002;360: 1347-60.

2. Lim SS, Vos T, Flaxman AD, et al. A comparative risk assessment of burden of disease and injury attributable to 67 risk factors and risk factor clusters in 21 regions, 1990-2010: a systematic analysis for the global burden of disease study 2010 . Lancet. 2012;380:2224-60.
3. Cloutier L, Morris D, Bruneau J, McLean D. World Health Organization celebrates World Health Day, April 7, 2013 - focusing on hypertension. Can J Cardiovasc Nurs. 2013;23(2):9-11.

4. Kearney PM, Whelton M, Reynolds K, Muntner P, Whelton PK, He J. Global burden of hypertension: analysis of worldwide data. Lancet. 2005;365:217-23.

5. Danaei G, Finucane MM, Lin JK, et al. National, regional, and global trends in systolic blood pressure since 1980: systematic analysis of health examination surveys and epidemiological studies with 786 country-years and 5.4 million participants. Lancet. 2011;377(9765):568-77.

6. Leenen FH, Dumais J, McInnis NH, et al. Results of the Ontario survey on the prevalence and control of hypertension. CMAJ. 2008;178(11):1441-9.

7. Statistics Canada. Canadian Health Measures Survey: blood pressure in adults [Internet]. Ottawa (ON): Statistics Canada; 2010 Feb 17 [cited 2014 Jul 7]. Available at: http://www.statcan.gc.ca/daily-quotidien /100217/dq100217b-eng.htm

8. Joffres M, Falaschetti E, Gillespie C, et al. Hypertension prevalence, awareness, treatment and control in national surveys from England, the USA and Canada, and correlation with stroke and ischaemic heart disease mortality: a cross-sectional study. BMJ Open. 2013;3(8):e003423.

9. Blais C, Rochette L. Surveillance de l'hypertension au Québec: incidence, prévalence et mortalité. Québec (QC): Institut national de sante publique du Québec; 2011. Available from: http://www.inspq.qc.ca/pdf /publications/1059_HypertensionArterielle.pdf

10. Robitaille C, Dai S, Waters C, et al. Diagnosed hypertension in Canada: incidence, prevalence and associated mortality. CMAJ. 2012;184(1):E49-56.

11. Chow CK, Teo KK, Rangarajan S, et al. Prevalence, awareness, treatment, and control of hypertension in rural and urban communities in high-, middle-, and lowincome countries. JAMA. 2013;310(9):95968 .
12. World Health Organization. Health impact assessment (HIA): the determinants of health [Internet]. Geneva (CH): World Health Organization; [cited 2014 Jul 7]. Available at: http://www.who.int/hia/evidence/doh /en/

13. Raphael D, editor. Social determinants of health: Canadian perspectives. Toronto (ON): Canadian Scholars’ Press; 2004.

14. Shah CP. Public health and preventive medicine in Canada (5th ed.). Toronto: Elsevier Canada; 2003.

15. Starfield B. Primary Care: Balancing health needs, services, and technology. New York: Oxford University Press; 1998.

16. Wilkinson R, Marmot M, editors. Social determinants of health. The solid facts (2nd ed.). Copenhagen: World Health Organization; 2003.

17. Sallis JF, Glantz K. Physical activity and food environments: solutions to the obesity epidemic. Milbank Q. 2009;87:123-54.

18. Lemstra M, Neudorf C, Opondo J. Health disparity by neighbourhood income. Can J Public Health. 2006;97:435-9.

19. Krieger J, Higgins DL. Housing and health: time again for public health action. Am J Public Health. 2002;92:758-68.

20. Lynch JW, Smith GD, Kaplan GA, House JS. Income inequality and mortality: importance to health of individual income, psychosocial environment, or material conditions. BMJ. 2000;320:1200-4.

21. Wood D. Effect of child and family poverty on child health in the United States. Pediatrics. 2003;112:707-11.

22. Gidlow C, Cochrane T, Davey RC, Smith G, Fairburn J. Relative importance of physical and social aspects of perceived neighbourhood environment for self-reported health. Prev Med. 2010;51:157-63.

23. Lee DS, Chiu M, Manuel DG, et al. Trends in risk factors for cardiovascular disease in Canada: temporal, socio-demographic and geographic factors. CMAJ. 2009;181(3-4): E55-66. 
24. Aubé-Maurice J, Rochette L, Blais C. Divergent associations between incident hypertension and deprivation based on different sources of case identification. Chronic Dis Inj Can. 2012;32(3):136-46.

25. Campbell NR, McAlister FA, Quan H; Hypertension Outcomes Research Task Force. Monitoring and evaluating efforts to control hypertension in Canada: why, how, and what it tells us needs to be done about current care gaps. Can J Cardiol. 2013;29(5):564-70.

26. Régie de l'Assurance Maladie du Québec (RAMQ). Banques de données: vue d'ensemble [Internet]. Québec (QC): RAMQ; [cited 2014 Jul 7]. Available at: http://www .ramq.gouv.qc.ca/fr/donnees-statistiques /Pages/donnees-statistiques.aspx

27. Ministère de la Santé et des Services sociaux du Québec. Cadre normatif Med-Écho - Mise à jour 2011 [Internet]. Québec (QC): MSSS; 2011[cited 2014 Apr]. Available at: http://msssa4.msss.gouv.qc.ca/fr/document /publication.nsf/0/581d207c3ed564a785257 4bf005283de?OpenDocument

28. Statistics Canada. Postal code conversion file (PCCF), reference guide: July 2009 postal codes [Internet]. Ottawa (ON): Statistics Canada; 2010. [Statistics Canada, Catalogue No.: 92-153-G]. Available from: www.statcan .gc.ca/pub/92-153-g/92-153-g2010001-eng.pdf

29. Gamache P, Pampalon R, Hamel D. Guide méthodologique : l'indice de défavorisation matérielle et sociale : en bref. Québec (QC): Institut national de santé publique du Québec; 2010. Available from: http://www2 inspq.qc.ca/santescope/documents/Guide_ Metho_Indice_defavo_Sept_2010.pdf

30. Statistics Canada. Age (123) and sex (3) for the population of Canada, provinces, territories, census divisions, census subdivisions and dissemination areas, 2006 census $100 \%$ data. Ottawa (ON): Statistics Canada; 2007. [Statistics Canada, Catalogue No.: 97551-X2006006].

31. Kadhim-Saleh A, Green M, Williamson T, Hunter D, Birtwhistle R. Validation of the diagnostic algorithms for 5 chronic conditions in the Canadian Primary Care Sentinel Surveillance Network (CPCSSN): a Kingston Practice-based Research Network (PBRN) report. J Am Board Fam Med. 2013;26(2): 159-67.
32. Lix L, Yogendran M, Burchill C, et al. Defining and validating chronic diseases: an administrative data approach. Winnipeg (MB): Manitoba Centre for Health Policy; 2006.

33. Hux JE, Ivis F, Flintoft V, Bica A. Diabetes in Ontario: determination of prevalence and incidence using a validated administrative data algorithm. Diabetes Care. 2002;25(3): 512-6.

34. Naessens JM, Baird MA, Van Houten HK, et al. Predicting persistently high primary care use. Ann Fam Med. 2005;3(4):324-30.

35. Stanton MW, Rutherford MK. The high concentration of US health care expenditures. Rockville (MD): Agency for Healthcare Research and Quality; 2005. (Research in Action 19, AHRQ no. 06-0060).

36. Statistics Canada. Statistical Area Classification (SAC) [Internet]. Ottawa (ON): Statistics Canada; [modified 2013 May 13; cited 2013 Jul]. Available at: http://www .statcan.gc.ca/pub/92-195-x/2011001/other -autre/sac-css/sac-css-eng.htm

37. Du Plessis V, Beshiri R, Bollman RD, Clemenson H. Definitions of rural. Rural and Small Town Canada Analysis Bulletin. 2001; 3:1-17. Available at: http://www.stat can.gc.ca/pub/21-006-x/21-006-x2001003-eng .pdf

38. Pampalon R, Raymond G. A deprivation index for health and welfare planning in Quebec. Chronic Dis Can. 2000;21(3):10413.

39. Pampalon R, Hamel D, Gamache P. Recent changes in the geography of social disparities in premature mortality in Quebec. Soc Sci Med. 2008;67:1269-81.

40. Martinez J, Pampalon R, Hamel D. Deprivation and stroke mortality in Quebec. Chronic Dis Can. 2003;24(2-3):57-64.

41. Pampalon R, Raymond G. Indice de défavorisation matérielle et sociale : son application au secteur de la santé et du bien-être. Santé, société et solidarité. 2003;1:191-208.

42. Philibert M, Pampalon R, Hamel D, Thouez JP, Loiselle CG. Material and social deprivation and health and social services utilisation in Quebec: a local-scale evaluation system. Soc Sci Med. 2007;64:1651-64.
43. Carr-Hill RA, Rice N, Roland M. Socioeconomic determinants of rates of consultation in general practice based on fourth national morbidity survey of general practices. BMJ. 1996;312(7037):1008-12.

44. Menec VH, Sirski M, Attawar D. Does continuity of care matter in a universally insured population? Health Serv Res. 2005; 40(2):389-400.

45. Mustard CA, Kaufert P, Kozyrskyj A, Mayer T. Sex differences in the use of health care services. N Engl J Med. 1998;338(23):167883.

46. Bertakis KD, Azari R, Helms LJ, Callahan EJ, Robbins JA. Gender differences in the utilization of health care services. J Fam Pract. 2000;49(2):147-52.

47. Redondo-Sendino A, Guallar-Castillón P, Banegas JR, Rodríguez-Artalejo F. Gender differences in the utilization of health-care services among the older adult population of Spain. BMC Public Health. 2006;16(6):155.

48. Public Health Agency of Canada. Tracking heart disease and stroke in Canada 2009. Ottawa (ON): PHAC; 2009.

49. Heart and Stroke Foundation of Canada; Canadian Cardiovascular Society; Health Canada. The growing burden of heart disease and stroke in Canada 2003. Ottawa (ON): Heart and Stroke Foundation of Canada; 2003.

50. Aubé-Maurice J, Rochette L, Blais C. Relation entre la défavorisation et l'incidence de l'hypertension artérielle chez les individus de 20 ans et plus au Québec en 2006-2007. Québec (QC): Institut national de santé publique du Québec; 2010.

51. Matheson FI, White HL, Moineddin R, Dunn JR, Glazier RH. Neighbourhood chronic stress and gender inequalities in hypertension among Canadian adults: a multilevel analysis. J Epidemiol Community Health. 2010;64(8):705-13.

52. Bell AC, Adair LS, Popkin BM. Understanding the role of mediating risk factors and proxy effects in the association between socioeconomic status and untreated hypertension. Soc Sci Med. 2004;59(2):275-83. 
53. Hawkley LC, Masi CM, Berry JD, Cacioppo $\mathrm{JT}$. Loneliness is a unique predictor of agerelated differences in systolic blood pressure. Psychol Aging 2006;21(1):152-64.

54. Pears E, Hannaford PC, Taylor MW. Gender, age and deprivation differences in the primary care management of hypertension in Scotland: a cross-sectional database study. Fam Pract. 2003;20(1):22-31.

55. Hammouche S, Holland R, Steel N. Does quality of care for hypertension in primary care vary with postcode area deprivation? An observational study. BMC Health Serv Res. 2011;11:297.

56. Brouwers FM, Courteau J, Grégoire JP, et al. The adequacy of pharmaceutical treatment of schizophrenia in Quebec varies with age, but is not influenced by sex or neighbourhood deprivation. Can J Psychiatry. 2013;58(8): 456-65.

57. Paré I, Ricard J. Le profil de pratique des médecins omnipraticiens québécois 20062007. Westmount (QC): Fédération des médecins omnipraticiens du Québec (FMOQ); 2007. 